\title{
EDUCAÇÃO INFANTIL: A CIDADE, O CURRÍCULO, A CULTURA DIGITAL
}

\author{
Maria da Graça Moreira SILVA ${ }^{1}$ \\ Fernando José ALMEIDA ${ }^{2}$
}

Resumo: Este artigo reflete sobre o diálogo emergente e necessário sobre a cidade, a escola, as crianças, o currículo, os educadores e o uso das tecnologias no contexto da escola. Reconhece as tensões, contradições e desigualdades que emergem desse contexto, em especial dos territórios vulneráveis de grandes centros urbanos e conceitua tanto o currículo quanto as tecnologias como direito público, gratuito e universal a ser assegurado. A construção deste currículo é tarefa histórica, recém-demandada à Escola do Brasil, pela escolha de seu modelo econômico e social. Desafio da sociedade, desafio das políticas públicas, direito da criança e dever do Estado.

Palavras-chave: Currículo. Educação infantil. Novas tecnologias na educação. Formação docente. Tecnologias da informação e comunicação.

\section{Introdução}

Os grandes municípios brasileiros, com suas complexidades, diversidades e distintos territórios, trazem, com suas dimensões, incomensuráveis desafios à educação do contingente de sua população. A despeito das diferentes naturezas desses desafios, este artigo foca a Educação Infantil pública, considerando o contexto educacional das crianças de 0 a 6 anos e reflete sobre o emergente e necessário diálogo entre o currículo, os educadores e as tecnologias de informação e comunicação. Tudo acontece num contexto singular, marcado pela quantidade de integrantes, diversidade de seus atores, interesses conflitantes, heterogeneidade dos processos e diferenças regionais.

Nesse contexto, também, as mídias e tecnologias da informação e comunicação (TIC) são consideradas como uma das catalisadoras deste debate - seus usos e impactos na aprendizagem, no ensino, nas relações pedagógicas, na democratização e na emancipação dos cidadãos.

Assim, o contexto da nova urbanidade, em especial dos territórios vulneráveis, exige que se construam a imagem e vida da uma nova criança que seja admitida,

${ }^{1}$ PUC - Pontifícia Universidade Católica de São Paulo - Departamento de Computação - Pós-graduação em Educação. São Paulo - SP - Brasil. 05014-901 - mgraca.moreira@ gmail.com

2 PUC- Pontifícia Universidade Católica de São Paulo. Faculdade de Educação - Departamento de Tecnologia da Educação. São Paulo - SP - Brasil. 05014-901 - fernandoalmeida43@ gmail.com 
respeitada e viva plenamente suas potencialidades e tem na escola e nas mídias e tecnologias seguramente uma aliança eficaz e complementar.

Não se limita este estudo à reflexão sobre os aspectos tecnicistas inerentes às tecnologias ou ao encantamento tecnológico que poderia ofuscar a prática pedagógica, mas esse estudo quer ampliar o debate e defende a luta política pela apropriação das tecnologias digitais da informação e comunicação, pois, como defendem os autores Almeida e Silva (2014).

A democratização e a melhoria da qualidade da educação não se desenvolvem espontaneamente do âmago das produções tecnológicas, mas são resultantes de amplo debate e da luta política pela apropriação das tecnologias, pelo acesso à sociedade em rede e pela inclusão ao modus vivendi da cultura - agora marcada indelevelmente pelo contexto digital. (ALMEIDA; SILVA, 2014, p.1240).

O diálogo sobre a cidade, a escola, as crianças, o currículo e os educadores deve prever o reconhecimento de que os relacionamentos humanos e práticas sociais contemporâneas são, segundo Schwartz (2014, p.87), “[...] redefinidos por sistemas de informação e comunicação cuja arquitetura responde cada vez mais aos imperativos de uma nova economia política do conhecimento adequada às moralidades pós-modernas".

Esse diálogo demanda a leitura do mundo contemporâneo de forma crítica, buscando trazer o contexto de Paulo Freire para os dias atuais. No cenário da cultura digital, o lançar sobre o mundo suas palavras podem ampliar as possibilidades de conferir voz ao professor e ao aluno e, por meio da expressão de suas vozes, empoderálos.

Este artigo reconhece as tecnologias como um direito humano e as trata a partir de suas finalidades educacionais, ou mesmo civilizatórias, entendendo que seus múltiplos usos estão presentes na escola. A recomposição e preparação dos currículos para esse desafio são de enorme urgência política e pedagógica.

Uma cidade que se queira educadora e comprometida com as próximas gerações deve estar marcada por princípios da aprendizagem como fator de humanização. Tal fundamento dos atos de aprender se baseia na superação da aprendizagem como uma forma individualista de ver e participar do mundo que parte do equivocado princípio que o isolamento e as conquistas individuais são as únicas que marcam o mundo dirigido unicamente para a competição e para o cinismo isolacionista. Nesse mundo a comunidade cede lugar aos condomínios intelectuais e territoriais transformando a 
cidade em espaços de desconvívio. O conceito de comunidade é substituído pelo conceito de imunidade. Isolam-se grupos e são imunizados dos problemas gerais do convívio e da partilha.

\section{A cidade e a criança}

O processo da urbanização vem definindo a busca e cumprimento do direito da educação escolar para todas as idades. As megalópoles, à medida que crescem se encolhem com relação ao atendimento de suas crianças. Fazem-nas nascer, mas negamlhes seus espaços. Os espaços diminuem em ambientes para muitas pessoas ou pátios inseguros, em jardins raros e distantes. Os territórios ocupados pelos veículos impedem as crianças de se apropriarem de árvores, praças e calçadas. Os espaços de esportes e de brinquedos se reduzem. A rua é espaço de perigo, agressão e de velocidade. São sinônimos do não espaço humano ou do espaço não humano.

No Brasil, este processo de urbanização corresponde a um novo modelo econômico, que desencadeado na década de 50 do século XX, se implantou de forma gradativa, mas imperiosa. Tal modelo caracterizou-se pela substituição do modelo agroexportador por uma economia urbana de mercado interno, sem perder algumas das características antigas.

É nesse contexto que se proliferam um dos novos modelos de família, a família nuclear urbana em territórios vulneráveis, que além de sua estrutura mínima, usualmente liderada pela figura feminina, marcada pelo trabalho diuturno dos adultos, e pelo isolamento prematuro das crianças em espaços, artificiais forjados no seio da cidade.

As habitações se restringem a pequenos cômodos ou aglomerados na periferia das cidades, distantes dos locais de trabalho de grande parte dessa população, “[...] marcada pelo preconceito, pela pobreza, pela ausência de uma rede de proteção social e por uma limitada presença do Estado.” (BATISTA; CARVALHO-SILVA, 2013, p.14). Usualmente esses espaços são caracterizados pela insalubridade e hostilidade da vizinhança.

Nesses espaços, a presença da TV e do computador ocupam local de destaque e status, assumindo diversos papéis, dentre os quais de entreter, de fazer companhia às crianças impedidas de brincar nos espaços públicos e de proteção. Há quem as use para 
distrair, acalmar ou passar o tempo das crianças como forma de liberar os adultos para as tarefas do seu dia a dia.

O computador é visto pelas mães desse grupo como um recurso de duplo objetivo. Se por um lado ele se presta a ser uma ferramenta para a realização de pesquisas e tarefas escolares, (portanto ligado à intensificação do trabalho da escola) por outro lado cumpre o papel de preencher as lacunas da falta de lazer no bairro tornando-se um aliado no controle do tempo livre das crianças (embora as mães pareçam não se preocupar com o controle do conteúdo acessado na internet). (BATISTA; CARVALHO-SILVA, 2013, p.221).

A cidade assim organizada, que reproduz a desigualdade social e geográfica, impele a criança ao convívio com poucos, ou mesmo a isolar-se passivamente diante da TV, de computadores ou de brinquedos eletrônicos no fundo de seu quarto ou dividindo-os com outras crianças em espaços exíguos.

O universo das histórias infantis, as cores e seus movimentos, as palavras originantes do vocabulário primitivo, os valores de viver em sociedade, os sons formadores do gosto estético, os enredos de mistério, de humor ou de heroísmo se formam pelos meios de comunicação de massa ditados pelos valores de consumo ou de homogeneização das culturas. Nesse contexto, os brinquedos artesanais desaparecem e os objetos de consumo induzido ganham prioridade e se tornam valores.

Segundo os dados do IBOPE (INSTITUTO BRASILEIRO DE OPINIÃO PÚBLICA E ESTATÍSTICA, 2013), as crianças passam de 3 a 5 horas diárias em frente à TV. A fraternidade da vizinhança vem sumindo. A partilha do brinquedo torna-se luta pela propriedade. Dentro deste contexto nascem a importância e o enraizamento cultural das tecnologias para a primeira infância. Os jogos eletrônicos, assim como os celulares multifuncionais, os brinquedos com programações para andar, correr, pular, voar tornam-se objetos de compra, de desejo, e não objetos da imaginação. Os contos de fadas que trazem os tapetes voadores ou os abre-te Sésamo como imaginação construtiva, desaparecem. Ao passo que os drones, os guindastes ou as bonecas que andam complementam suas habilidades nos desenhos ou nas histórias em quadrinhos na TV ou na internet. A imagem substitui ou supera a imaginação.

A TV universaliza o imaginário, responde com formulações do código social às questões mais subjetivas e não contrárias em nenhum momento pela lógica da realização de desejos. Quem poderá desencantar esta criança, bela adormecida enfeitiçada pelo espelho que só responde sim às suas tentativas de ficar onipotente? 
Quem poderá despertá-la de seu sonho de alienação e devolve-la ao mundo onde convivem homens e mulheres? Um beijo de amor, diz a lenda. E aqui cabe lembrar que o mundo desta criança já foi povoado antes que ela tenha sido entregue aos cuidados da TV (KEHL, 1995).

Assim, o tempo em que a criança passa em frente à TV ou ao computador consumindo passivamente é desproporcional com o tempo de quatro horas em que permanece na escola.

Estudos da MilwardBrown (2014) apontam que brasileiros ficam quase oito horas por dia em frente a alguma tela, ou em várias telas simultaneamente (internet, TV, celular etc.). O tempo da criança na escola, assim, deve ser dilatado em atividades de outras dimensões.

Porém, a escola, por desconhecimento ou temor, não pode cair na tentação de se afastar ou afastar as crianças do acesso, contato e inserção à cultura digital, pois “[...] os esforços empregados para aumentar as oportunidades também podem levar a maiores riscos, enquanto esforços para reduzir riscos podem restringir as oportunidades das crianças e adolescentes". (LIVINGSTONE, 2014, p.34).

\section{A cultura digital}

Prado e Silva (2009) destacam que as crianças chegam às escolas, inclusive na educação infantil, com um vasto repertório de contato com as mídias. Para Gadotti (2005) a cultura midiática constitui-se a cultura primeira do aluno por força da sociedade em que vive. Em geral, independente da região do país, os alunos passam, em menor ou maior grau, por experiências anteriores com uma multiplicidade de mídias como: horas frente à TV, contato com rádio, exposição às peças promocionais de mídia exterior (outdoors, cartazes), além dos vídeos, DVD e computadores e internet. Schwartz $(2014$, p.88) ressalta que "[...] crianças e adolescentes são os principais portadores dessa vida digital anterior à escola e, cada vez mais, interpondo-se às relações familiares e sociais".

A Educação Infantil, de 0 a 6 anos, no contexto da sociedade massiva, competitiva, com um modelo de família fragmentada, habitantes dos territórios vulneráveis de grandes centros urbanos, assume a tarefa de atender à demanda social de cuidar da criança, abrigá-la, alimentá-la, desenvolver suas capacidades de convívio social, instruí-la, formar nela valores de humanização, prepará-la para o mundo do 
conhecimento. Tarefa nada fácil, num período diário curto de tempo diário, posta à escola que a assume com coragem e despreparo.

As escolas recebem uma criança já exposta aos meios de comunicação, mídias e tecnologias digitais, no entanto, Martin-Barbero (1996, p.12) pontua que:

[...] a simples introdução dos meios e das tecnologias na escola pode ser a forma mais enganosa de ocultar seus problemas de fundo sob a égide da modernização tecnológica. O desafio é como inserir na escola um ecossistema comunicativo que contemple ao mesmo tempo: experiências culturais heterogêneas, o entorno das novas tecnologias da informação e da comunicação, além de configurar o espaço educacional como um lugar onde o processo de aprendizagem conserve seu encanto.

É comum encontramos crianças com menos de um ano inserindo DVD em computadores, operando o controle remoto da TV ou tocando nas telas de tablets para acessarem seus aplicativos, vídeos, jogos ou músicas favoritos. As crianças fazem isso como mero mimetismo, reproduzindo o que viram. Elas não aprendem, fazem daquilo um uso mecânico, repetitivo e impensado. Essa habilidade é simples, não passa do domínio das teclas, telas, de ligar, desligar ou mudar de canal.

\section{A pesquisa TIC Kids Online Brasil 2012 (COMITÊ GESTOR DA INTERNET} DO BRASIL, 2012, p.31) aponta que "[...] crianças com idades abaixo dos 10 anos que começaram a usar a internet representam $44 \%$ dos respondentes". A mesma pesquisa produziu dados que evidenciam que uma média de $9 \%$ das crianças brasileiras de até 6 anos já acessaram a internet pela primeira vez. Entre a classe C, 8\% delas acessaram até os 6 anos e 4\%, da classe D e E. A tendência é que este número cresça nos próximos anos.

A internet via telefone ou computador, já é realidade à vida da criança. E como a internet entra neste contexto? Segundo pesquisa da Fundação Telefônica (2014), hoje $53 \%$ das crianças utiliza o celular para jogar; $43 \%$ o utilizam para conversar e outros $26 \%$ para enviar e receber mensagens de texto (SMS) - seja através dos videogames tradicionais ou dos jogos online no computador, que podem ser jogados com amigos via internet.

Porém, o desafio de enfrentar, ensinar e aprender a viver na cultura digital é de outra natureza, que apenas a espontaneidade da aprendizagem não o faz. $\mathrm{O}$ desafio da escola e dos educadores é o de contar com o mimetismo espontâneo das crianças e extrair daí os valores próprios do experimentar, do espantar-se, do repetir (às vezes até a 
exaustão), do imaginar, do prever, do modificar, do estimar, como sempre o fizeram com a caixa de sapato, com as garrafas plásticas, com os potes de iogurte, com as bonecas velhas e quebradas, com as bolas de meia. Por aí passa o início do domínio da cultura digital.

Mais do que os dados estatísticos, o primordial é a tendência que se marca entre as crianças e jovens sobre a importância da escola, o que indica a necessidade de iniciar o trabalho crítico com as mídias e tecnologias para que tal tendência reverta-se. E o início se dá na Educação Infantil.

\section{Educação infantil e novos letramentos}

O uso intensivo das tecnologias, associadas aos demais desafios da contemporaneidade, provoca mudanças no cotidiano e na ecologia da escola, seja por meio dos novos signos que fluem nas redes conectadas, na construção de novas sociabilidades ou na edificação das relações de poder, configurando-se "[...] como uma espécie de modus vivendi, como um processo social que determina as reconfigurações identitárias dos indivíduos.” (ZUIN, 2010, p.967). Esse modus vivendi se mostra como uma das características da cultura.

A cultura digital não é conceituada pelo determinismo das mídias ou tecnologias, mas emerge como causa e em decorrência de seu uso e de sua apropriação social no dia a dia e as novas demandas que emergem de seu uso. O contexto da cultura digital oportuniza expressão da voz dos professores e dos alunos e favorece o processo de apropriação social da tecnologia e seu uso inovador na educação e sua articulação ao currículo. "É o currículo que define o uso das TIC e não é definido por ela. Defende-se também neste artigo que o currículo esteja integrado à cultura contemporânea como um direito." (ALMEIDA; SILVA, 2014, p.1236).

O início do século XXI veio alargar o conceito de alfabetização estendendo-o ao letramento matemático, ao letramento científico, ao letramento tecnológico, assim como, o letramento funcional, que exige que não apenas se caminhem sobre as letras, como dizia Paulo Freire, mas que se consiga ler e interpretar o mundo e lançar nele suas palavras. Fica evidenciado que o cidadão que não lê, não letrado, tem maior dificuldade de ler e interpretar o projeto sociocultural da nação, para dele participar ou criticar. $\mathrm{O}$ analfabetismo carrega em si inúmeras faces perversas que desfibram uma nação, assim como gerações inteiras de famílias e de regiões. O analfabetismo da leitura de textos e 
números é a base de menor participação social. Carência que se revela como a maior dívida educativa de nossas metrópoles

O conceito de letramento, em debate entre os educadores desde a década de 1980, pode ser empregado para ampliar a compreensão sobre o aprender a ler criticamente e escrever (autorar) na cultura digital. O letramento não se relaciona apenas à leitura e escrita, mas à participação em diferenciadas formas de discurso,

[...] letramento é a condição de ensinar e aprender as práticas sociais da leitura e da escrita. É o trabalho que o educador infantil realiza na sua sala de aula, oportunizando às suas crianças todo tipo ou vários tipos de linguagens escritas e orais, tais como: livros infantis, receita culinária, bula de remédio, jornais, revistas, cartas, bilhetes, rótulos e tudo que lemos e escrevemos da nossa realidade. (SOUZA, 2008, p.276).

Os processos de letramento, que têm múltiplas conotações, iniciam-se para a criança em várias frentes. Uma delas é a educação para o olhar, a se iniciar desde os primeiros meses de vida. Cores, formas, movimentos, repetições são elementos da cultura que estimulam a imaginação, a percepção, a discriminação de imagens, a relação entre as formas, as cores e até o humor. A família, os amigos, os meios de comunicação e os professores iniciam esse complexo processo de letramento que inclui diferenciação, repetição, estímulos, interações verbais, que permitem formar vínculos afetivos e significativos com o mundo das imagens. A simples exposição das crianças ou dos bebês às imagens, sem interação com o adulto ou seus pares, não faz os efeitos de valorização da aprendizagem a que aqui se refere.

No contexto institucional da escola, alfabetização visual significa desenvolver sistematicamente as habilidades envolvidas na leitura de imagens, de modo a levar ao compartilhamento de significados atribuídos a um corpo comum de informações. Diante disso, nada poderia ser mais plausível, e mesmo necessário, que a imagem possa adquirir na escola a importância cognitiva que merece nos processos de ensino e aprendizagem. Educa-se assim para novas formas de olhar, para novas leituras que a cultura das mídias digitais traz ao cotidiano de nossas crianças: uma nova linguagem.

Assim, o letramento se dá desde o nascimento, pelo contato e interação da criança com o mundo, com os signos, imagens, figuras, letras, números e tudo que possa ter um significado para a linguagem escrita. Segundo esse entendimento, Damázio e Souza (2014) chamam a atenção de que crianças expostas desde cedo ao convívio com o 
mundo da leitura e da escrita, vivenciam o letramento em seu próprio meio social. Porém, “[...] crianças cujas famílias são pouco alfabetizadas, elas podem iniciar um processo de expropriação do mundo da escrita, entendendo o texto escrito como apenas um recurso do universo escolar, não dando significado às funções sociais da linguagem". (DAMÁZIO; SOUZA, 2014, p.6592).

O trabalho da escola, em especial da educação infantil, é dessa natureza, demanda estimular a criança a

[...] participar ativamente do processo de construção da leitura e da escrita do seu mundo e não do mundo do educador ou dos autores de cartilhas e livros didáticos. Fazer com que as crianças tenham liberdade de expressão e que possam experimentar as múltiplas linguagens, como a música, dança, artes, leituras da literatura infantil clássica e brasileira, histórias em quadrinhos, jogos, brinquedos e brincadeiras e tantas outras. (SOUZA, 2008, p.227).

A educação infantil, dessa forma, a autora complementa

[...] parte do princípio do que a criança sabe, o que faz parte do seu meio sociocultural, trabalhando com as práticas sociais da leitura e da escrita. Identificando toda manifestação de leitura e de escrita da criança como algo singular e mediado de significado. (SOUZA, 2008, p.277).

Na cultura digital, cabe, bem no início da vida da criança, a formação de seu o olhar que discrimina e percebe valores e matizes. Sobre a interação da criança com as mídias e tecnologias, Almeida e Silva (2010) destacam a importância da presença e mediação de outro, como algum membro da família ou professor, e são os elementos constitutivos desta formação.

Além disso, as facilidades de acesso aos dispositivos móveis que contém aparelhos fotográficos, disponíveis a preços sempre menores, trazem aos usuários mirins, a possibilidade de acessos às redes de visualização de fotos, à produção difusão e ao culto sempre maior, por exemplo, das selfies. Embora como fenômenos específicos (instagram, selfies etc.) eles sejam passageiros, mas a ampliação da captura de imagens, instantaneamente vistas e partilhadas, é uma cultura a permanecer e a ser estudada pelos educadores.

Para Rojo (2013) esse novo letramento, o letramento digital, não é unicamente resultado dos letramentos com os avanços tecnológicos, mas se relaciona a uma nova 
mentalidade, consequente da "[...] integração de semioses, o hipertexto, a garantia de um espaço para a autoria e para a interação, a circulação de discursos polifônicos, num mesmo ciberespaço" (ROJO, 2013, p.8) que desenham novas práticas.

Envolve esse novo letramento a interação com os aparelhos tecnológicos e seus programas. Todos os aparelhos tecnológicos e seus programas supõem algum grau de manipulação humana para dar-lhes significado. O nível crescente de manipulação humana indica a valorização do aparelho. Assistir um programa de TV é diferente, do ponto de vista de interação, de jogar um jogo eletrônico ou de assistir a um vídeo na internet.

Aparelhos simples são de operação quase transparente à criança permitindo a ela perceber seus engenhos e facilitar-lhes sua interferência neles. Por exemplo, a criança ao desmontar um carro de mecânica simples ou uma boneca para ver suas engrenagens e mecanismos prevê que possa descobrir-lhes os mistérios. São os primeiros sinais do senso de investigação e curiosidade, mediados pela intervenção.

No entanto, há aparelhos tão complexos (brinquedos, motores, máquinas, sensores, telefones) que prescindem quase totalmente da manipulação significativa da criança. Outros são complexos, mas exigem participação ativa intencional, mecânica e reflexiva da criança, como linguagens de programação para crianças, a robótica educacional e a construção de protótipos ou experimentos, no letramento, na articulação do uso das TIC ao currículo, à curiosidade epistemológica, à interdisciplinaridade, à interação e à ação da criança.

É função da escola em seu planejamento e com seus pares fazer a análise das potencialidades das mídias e tecnologias para estimular a desenvoltura da criança nas habilidades do pensamento e do convívio.

Os objetos tecnológicos mediadores do conhecimento e do convívio se imiscuem cada vez mais em nosso cotidiano exigindo que sejam tratados não apenas como objetivos, mas como produtores de subjetividades. Os mediadores de acesso ao mundo não são neutros pela sua origem e pelo significado que já trazem dentro de si ao serem usados. Têm alguma subjetividade e intencionalidade na sua origem, pois são produtos humanos, advindo de uma cultura, de uma economia, de um programa intencional de finalidades. No caso dos produtos de uma sociedade de consumo, pode-se a priori prever seus fins mais marcantes.

Os objetos-aparelhos são objetos de nossas ações, mas aos poucos escorregam de nossas mãos e nos ajudam a intervir no mundo de outros objetos e por isso, vão se 
tornando coadjuvantes de nosso pensamento, e nesse sentido começam a se tornar companheiros de nosso pensar. Ascendem assim a certo grau de subjetividade perante a subjetividade humana. As tecnologias os instrumentos são tomados pelo sujeito como um objeto e com eles age sobre outros objetos. A partir disso, eles ganham certo estatuto de sujeito.

Assim, se constroem no mundo da educação ou da comunicação uma rede de objetos-sujeitos que vão criando uma nova subjetividade técnica. Embora pareça uma obra imaginativa de ficção trata-se de uma dimensão filosófica de provocação ao estudo das mídias e tecnologias que se direcionam ao trabalho pedagógico escolar.

Eles, os objetos-tecnológicos, agem sobre os sujeitos pessoais a quem eles servem. A tarefa do educador que se dedica à formação de crianças e jovens ou dos educadores que são gestores de políticas públicas é a de debruçarem-se continuamente na análise filosófica de tais questões. Ao contrário, os educadores têm se restringido a destacar a dimensão da motivação e da eficácia da aprendizagem mediada por tecnologias digitais, e deixam passar ao largo a dimensão filosófica da questão. A subjetividade do sujeito.

Assim as tecnologias da informação e da comunicação são consideradas como um Direito Humano, pois todas as tecnologias podem ser entendidas como produtos da humanidade adensada, uma vez que foram construídas por muitos, em tantos séculos que nos precederam, em forma de trabalho para criar as condições materiais e intelectuais para a vida. As ciências e as artes, as histórias e a apropriação cognitiva do território compõem o quadro total da compreensão do currículo escolar.

O trabalho educacional com elas não pode se reduzir ao mero preparo para a alfabetização, pois elas têm características de vida no mundo emocional, criativo, relacional e intelectual que gozam de objetos e atividades próprias. São humanos.

O tempo do atendimento vivenciado pela escola não é suficiente para tais desafios, pois esta faixa etária exige tempo integral, cuidados iniciais intensivos, programas e aparelhamentos lúdicos, criativos, formação de indicadores de qualidade da educação infantil, formação em serviço de educadores, entre outros.

A educação para crianças de 0-3 anos requer investimentos independentes das disputas e pressões que existem para o atendimento das demais crianças e outros graus de ensino, levando sempre em conta que tais recursos não são gastos, mas são investimentos, no presente e para o futuro. 


\section{Considerações}

As crianças de menos de 6 anos foram entendidas por milhares de anos no ocidente, como incapazes de aprendizagem significativas ou reconhecidas. Por isso, a questão curricular nunca foi debatida ou analisada como algo que lhes coubesse. Um brincar desvalorizado ou um silêncio subserviente lhes couberam durante séculos.

$\mathrm{O}$ acesso e permanência das crianças frente à TV, aos computadores, jogos e internet comum nas megalópoles, em especial em seus territórios mais vulneráveis, bem como a manipulação espontânea de telas e teclas, são considerados conhecimentos ou explorações cotidianas. A leitura crítica e o escrever (autoria) na cultura digital envolvem produzir cultura, não apenas navegar por ela.

Aprender, ser letrado e alfabetizado, ser produtor de conhecimentos epistemológicos na cultura digital vai mais além do que a manipulação de telas, imagens e teclas. Buscar o domínio da cultura digital e de suas formas de pensar que são as de sempre, agora com sabor do modus vivendi dessa nova cultura. Esse é o desafio dos pais, das famílias, dos educadores na escola, da sociedade nas múltiplas instituições sociais e das políticas públicas.

Sendo assim, cabe à Educação Infantil e à escola reorganizar seus currículos principalmente para as crianças de 0 a 6 anos. Não se trata de uma construção óbvia. $O$ currículo é visto neste artigo como uma peça cultural que faz com que se possa planejar e realizar o ingresso das crianças em um mundo humano de direitos, de conhecimentos e de rico convívio. Tarefa absolutamente complexa, inovadora e contínua.

O currículo se planeja à luz do projeto de sociedade desenhado politicamente para um país, e a partir, dele traçam-se os percursos de experiências cognitivas que alunos, professores e comunidade educativa terão para viver experiências de conhecimento. O currículo para Educação Infantil representaria, neste início de século XXI, uma retomada da criança como um ser que em tudo é humano e tem direito de acesso e respeito pleno ao desenvolvimento de seus processos internos de conhecimento. O currículo parte também do conceito de ser humano, de sociedade justa, de conceito de conhecimento como algo que constitui a pessoa equipada para viver em sociedade livre e solidária.

Formas comprometidas de acompanhar o desenvolvimento da pessoa, valorização do ato de aprender e produzir conhecimento, apoio à autoria e à criatividade, criação de ambientes de convívio, para a construção coletiva de 
conhecimento, disponibilização de mediadores sociais e tecnológicos que catalisem situações de experimentações de pesquisas são os componentes básicos de um currículo.

A construção deste currículo é tarefa histórica, recém-demandada ao Brasil, pela escolha de seu modelo econômico e social. Desafio da sociedade, desafio das políticas públicas, dever do Estado.

O diálogo emergente e necessário sobre a cidade, a escola, as crianças, o currículo e os educadores no contexto da escola pública crianças de 0 a 6 anos apenas se inicia. Este traduz a complexidade de interesses e de conveniências com que o mundo e a cultura digital e as características dos atuais aglomerados urbanos chegam até as crianças de 0 a 6 anos, como não o fazia há 20 anos. Assim, as crianças de 0 a 6 anos são sujeitos do processo curricular a ser planejado pela sociedade, pelo estado, pela escola, pela comunidade expressos nos planos de trabalho de cada professor.

É uma realidade o isolamento da criança e a terceirização dos cuidados familiares das crianças de 0-3 anos para cuidadores ou para irmãos um pouco mais velhos. A escola surge neste novo cenário, além de um espaço de proteção, como um espaço onde se concretizam os direitos sociais e humanos, refletindo o conceito de criança cidadã com perspectivas de educação e cuidados. No entanto, como fenômeno social massivo, o poder público não se adaptou a tal atendimento no mesmo ritmo do crescimento da demanda. Transporte, espaços adequados, tempo integrais na escola, formação de profissionais educadores especializados, conceito de currículo para integrar tais idades às finalidades educativas inexistem ainda como política de atendimento.

\title{
EARLY CHILDHOOD EDUCATION: THE CHILDREN AND THE CURRICULUM AND THE DIGITAL CULTURE
}

\begin{abstract}
This article reflects on the emerging and necessary dialogue about the city, school, children, the curriculum, educator, and the use of Information and Communication Technology. It acknowledges the concerns, contradictions and inequalities that arise from this context, especially the vulnerable areas of large urban centers and conceptualizes both the curriculum and technology as a public, free and universal granted right. The development of this curriculum is a historical issue, newly demanded to Brazil School, by choosing its economic and social model. It is a challenge to society, to the public policy, and it is children's right and State's responsibility.
\end{abstract}

Key words: Curriculum. Early childhood education. New technologies in education. Teacher training. Information and communication technology (ICT). 


\section{REFERÊNCIAS}

ALMEIDA, F. J.; SILVA, M. G. M. Cultura digital e currículo como direito. Revista Científica e-Curriculum, São Paulo, v.2, n.12, p.1233-1248, mai./out. 2014.

Disponível em:

<file:///C:/Documents\%20and\%20Settings/Gra\%C3\%A7a/Meus\%20documentos/Down loads/20229-53381-3-PB.pdf> . Acesso em: 10 jun. 2015.

ALMEIDA, M. E. B.; SILVA, M. G. M. Internet na infância: um retrato do uso das TIC por crianças de 5 a 9 anos no Brasil. In: BARBOSA, A. Pesquisa sobre o uso das Tecnologias de Informação e Comunicação no Brasil 2005-2009. São Paulo: Comitê Gestor da Internet no Brasil, 2010. p.37-43.

BATISTA, A. A. G.; CARVALHO-SILVA, H. H. Família, escola, território vulnerável. São Paulo: CENPEC, 2013.

COMITÊ GESTOR DA INTERNET DO BRASIL - CGI.br. Relatório metodológico TIC educação 2013. Pesquisa sobre o uso das tecnologias de informação e comunicação nas escolas brasileiras: TIC Educação 2013. São Paulo: Comitê Gestor da Internet no Brasil, 2014.

DAMÁZIO P.; SOUZA, R. A. M. Letramento na concepção de Vigotski: o papel do/a professor/a na apropriação da linguagem oral e escrita pela criança. In: II CONGRESSO NACIONAL DE FORMAÇÃO DE PROFESSORES XII CONGRESSO ESTADUAL PAULISTA SOBRE FORMAÇÃO DE EDUCADORES, 2014, Lindoia. Anais... Lindoia: UNESP, 2014. p.6590-6598.

FUNDAÇÃO TELEFÔNICA (Org.). Juventude conectada. São Paulo: Fundação Telefônica, 2014.

GADOTTI, M. A escola frente à cultura mediática. In: OROFINO, M. I. Mídias e mediação escolar: pedagogia dos meios, participação e visibilidade. São Paulo: Cortez. Instituto Paulo Freire, 2005. p.21-25. (Guia da Escola cidadã, 12).

INSITUTO BRASILEIRO DE OPINIÃO PÚBICA E ESTATÍSTICA - IBOPE. IBOPE Inteligência. [Online]. 2013. Disponível em: <http://www.ibope.com.br/ptbr/Paginas/home.aspx>. Acesso em: 10 jun. 2015.

KEHL, M. R. Imaginário e pensamento. In: SOUZA, M. H. (Org.). Sujeito, o lado oculto do receptor. São Paulo: Brasiliense, 1995. p.169-180.

LIVINGSTONE, S. Recomendações baseadas em evidências para pais, professores e formuladores de políticas públicas: uma visão da Europa. In: COMITÊ GESTOR DA INTERNET DO BRASIL - CGI.br. Pesquisa sobre o uso das tecnologias de informação e comunicação no Brasil: TIC Kids Brasil online 2013. São Paulo: Comitê Gestor da Internet no Brasil, 2014. p.53-62.

MARTIN-BARBERO, J. Heredando el futuro: pensar la educación desde la comunicación. Nómadas, Bogotá, n.5, p.10-22, set. 1996. 
MILLWARDBROWN. AdReaction. Marketing in a multiscreen world. [S.1.]: MillwardBrown, 2014. Disponível em:

<http://www.millwardbrown.com/adreaction/2014>. Acesso em: 10 jun. 2015.

PRADO, M. E. B. B.; SILVA, M. G. M. Formação de educadores em ambientes virtuais de aprendizagem. Em Aberto, Brasília, v.22, n.79, p.61-74, 2009.

ROJO, R. (Org.) Escol@ conectada: os multiletramentos e as TICs. São Paulo: Parábola, 2013.

SCHWARTZ, G. Os videogames e a morte dos professores. In: BARBOSA, A. F. Pesquisa sobre o uso das tecnologias de informação e comunicação nas escolas brasileiras: TIC Educação 2013. 1.ed. São Paulo : Comitê Gestor da Internet no Brasil, 2014. p.87-92.

SOUZA, R. A. M. Letramento na educação infantil: "quem tem medo do lobo mau [...]”. Revista Inter Ação, [S.1.], v.33, n.2, p.265-279, dez. 2008. Disponível em: <http://h200137217135.ufg.br/index.php/interacao/article/view/5267/4670>. Acesso em: 10 mai. 2016.

ZUIN, A. S. S. O Plano Nacional de Educação e as tecnologias da informação e comunicação. Educação e Sociedade, Campinas, v.31, n.112, p.961-980, jul./set. 2010. 